\title{
NOTES
}

\section{Electron Microscopy of Magnesium-Depleted Bacteria}

\author{
COUNCILMAN MORGAN, HERBERT S. ROSENKRANZ, BETTY CHAN, AND HARRY M. ROSE \\ Department of Microbiology, College of Physicians and Surgeons, Columbia University, New York, New York
}

Received for publication 8 November 1965

An electron microscope was used to examine bacteria after depletion of ribosomes. Advantage was taken of the fact that incubation of Escherichia coli in media devoid of magnesium causes loss of ribosomes without concurrent loss of viability (McCarthy, Biochim. Biophys. Acta

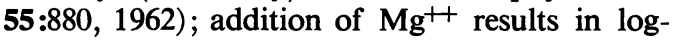
arithmic growth after a 5- to 6-hr delay. During this delay, a "nascent ribosomal ribonucleic acid (RNA)" accumulates (Suzuki and Hayashi, Biochim. Biophys. Acta 87:610, 1964), and this is followed by the production of $30 S$ and $50 S$ ribosomal subunits.

The bacterial strain used in this study was $E$. coli B. Growth, magnesium depletion, and repletion were carried out as described by $\mathrm{McCar}$ thy. For electron microscopy, the bacteria were fixed for $3 \mathrm{hr}$ at $4 \mathrm{C}$ in $1 \%$ glutaraldehyde (phosphate-buffered at $p \mathrm{H} 6.1$ ) to which $0.2 \%$ magnesium had been added. After washing, the bacteria were postfixed in $1 \%$ osmium tetroxide for $3 \mathrm{hr}$. Double fixation was employed, because it appeared to preserve the ribosomes better than did osmium tetroxide alone. After dehydration in ethyl alcohol, the cells were embedded in Epon 812 and sectioned. Details of the method are described elsewhere (Margaretten et al., J. Bacteriol. $91: 823$ ). The sections were stained with uranyl acetate followed by lead citrate.

Figure 1 shows the typical appearance of control bacteria grown in the presence of magnesium. Nuclear material is characterized by areas of low density containing filaments, which differ in thickness and are frequently branched. This appearance is in striking contrast to the fine, uniform filaments encountered after fixation in $1 \%$ osmium tetroxide with $0.01 \mathrm{M} \mathrm{Ca}^{++}$and $0.1 \%$ tryptone added (Kellenberger, Séchaud, and Ryter, Virology 8:478, 1959), or after formalin followed by osmium (Cota-Robles and Coffman, J. Bacteriol. 86:266, 1963). Ribosomes are so densely packed within the cytoplasm that superimposition makes it difficult to determine their arrangement. The plasma membrane is closely applied to the cell wall, but can be dis- tinguished from it in cross section. When considerably thinner sections were employed, many of the ribosomes were more clearly demarcated. Study of bacteria, such as the one illustrated in Fig. 2, revealed ribosomes dispersed at random and measuring about $180 \mathrm{~A}$ in diameter. This is within the range of size encountered in electron microscope examination of purified preparations of the $70 \mathrm{~S}$ ribosome component after metal shadowing (Hall and Slayter, J. Mol. Biol. 1:329, 1959) or staining (Huxley and Zubay, J. Mol. Biol. 2:10, 1960). It is of interest that no aggregation of ribosomes was apparent on the plasma membrane, suggesting that ribosomes are not preferentially attached to it.

After magnesium depletion for $24 \mathrm{hr}$, the ribosomes could no longer be distinguished (Fig. 3). The nuclear material frequently became fragmented and more widely distributed. Dividing cells were not encountered. At $6 \mathrm{hr}$ after the addition of magnesium (Fig. 4), the ribosomes again were evident, but they appeared to be smaller than those observed in controls, a finding consistent with the observation that $30 S$ and $50 S$ ribosomes are synthesized first (McCarthy, Biochim. Biophys. Acta 55:880, 1962). A surprising feature was the apparent reduplication and infolding of the plasma membrane, which was encountered at 6 and $9 \mathrm{hr}$ after replacement of magnesium. At the left of Fig. 4, near one end of the bacterium, small segments of two membranes have been cross-sectioned, revealing septa. Near the lower border of the same cell, the membranes are probably oblique to the plane of section and hence ill-defined, although the parallel septa can be made out. In Fig. 5, also illustrating a bacterium $6 \mathrm{hr}$ after addition of magnesium, there are two rows of parallel membranes. Those nearest the cell wall exhibit clearly defined septa along part of their course. The inset shows a section through the tip of a bacterium at right angles to its long axis. The cell wall is poorly defined, because of its oblique position. Near the center, a membrane is presumably parallel to the section, whereas the septa 

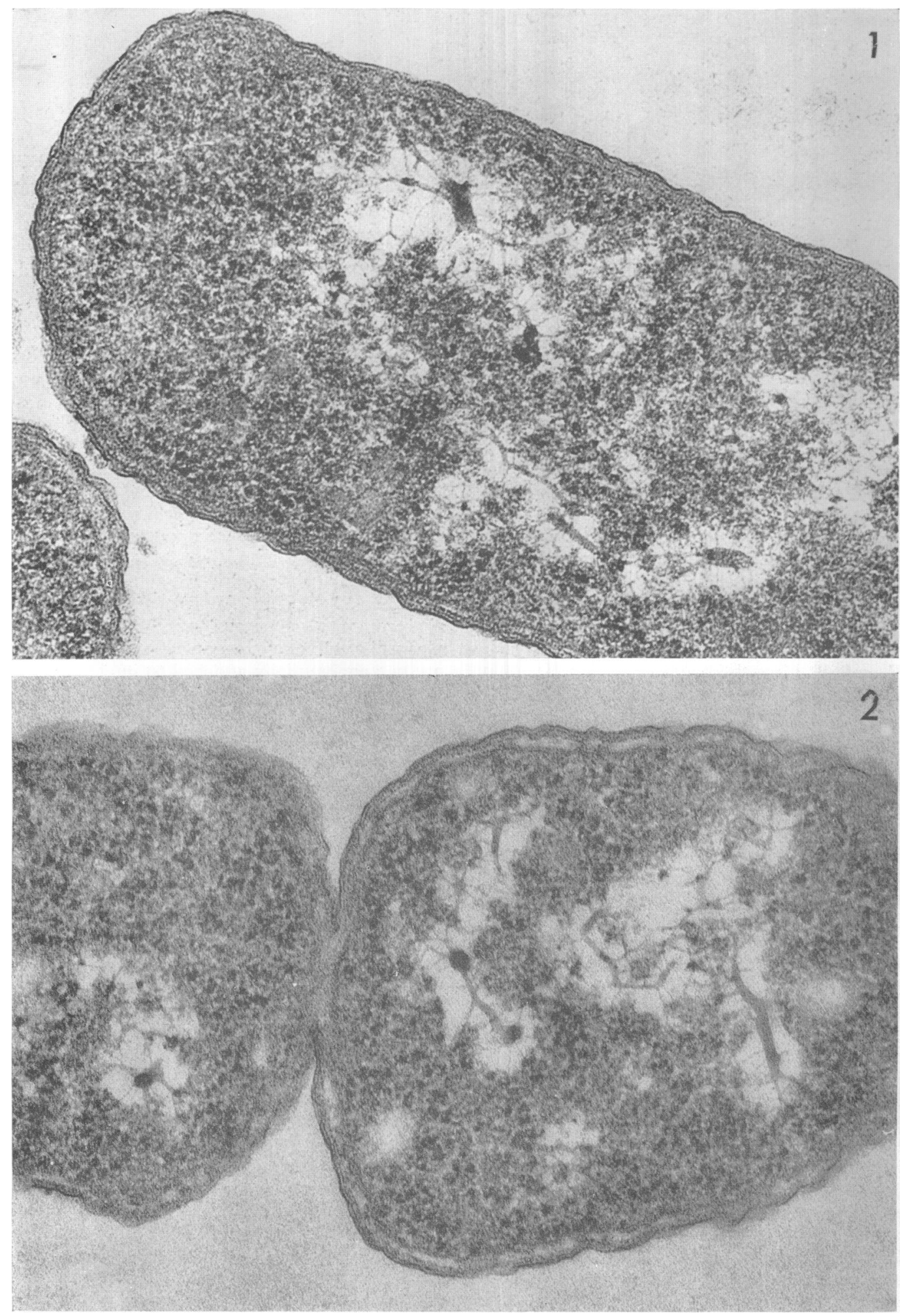

FIG. 1. Bacterium after fixation in gluteraldehyde and osmium tetroxide. $\times 110,000$.

FIG. 2. Thinner section through a bacterium which has nearly completed division. $\times 110,000$. 

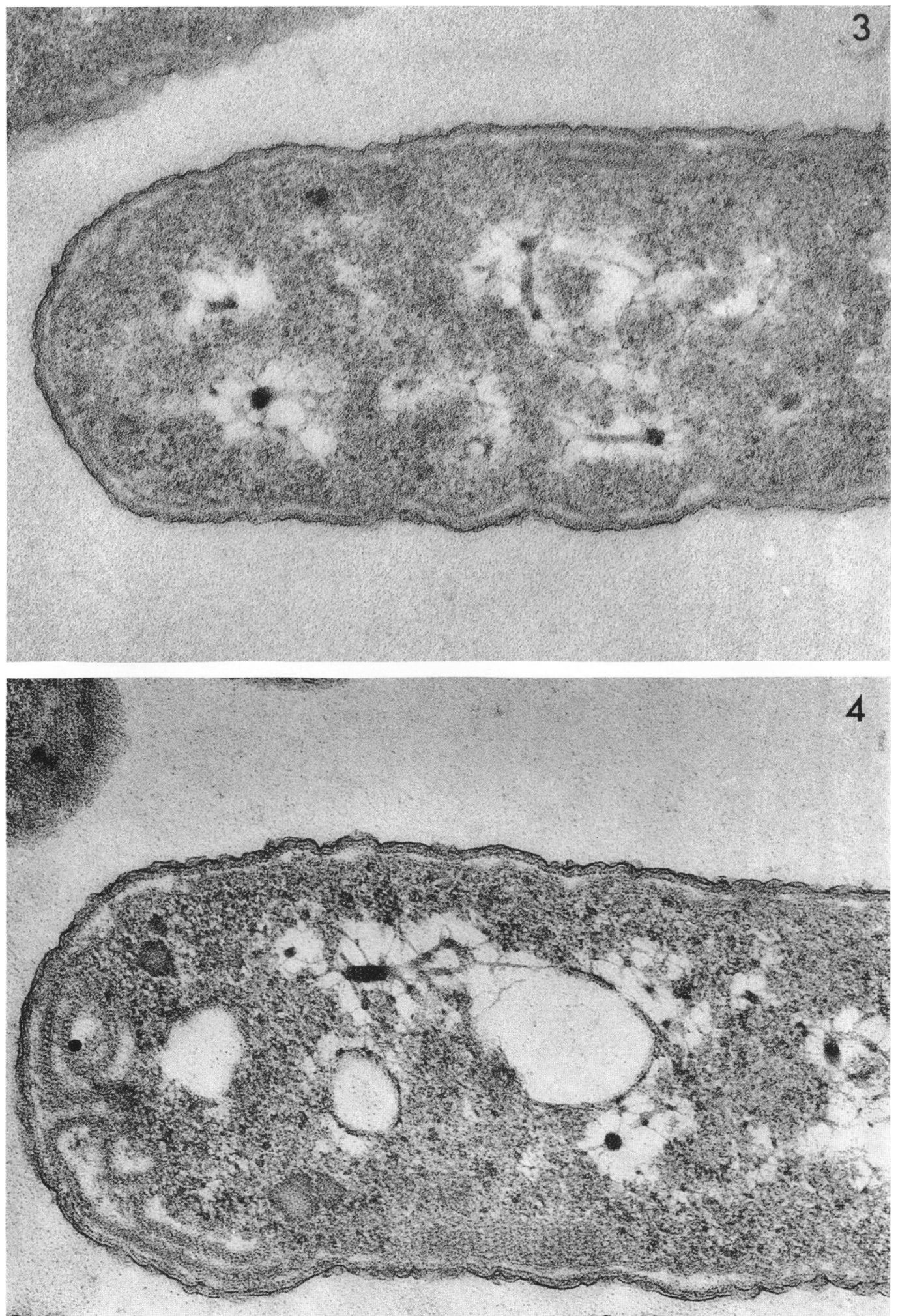

FIG. 3. Bacterium after magnesium depletion. $\times 110,000$.

FIG. 4. Six hours after addition of magnesium. There are several vacuoles, one of which is continuous with the nuclear material. $\times 110,000$. 


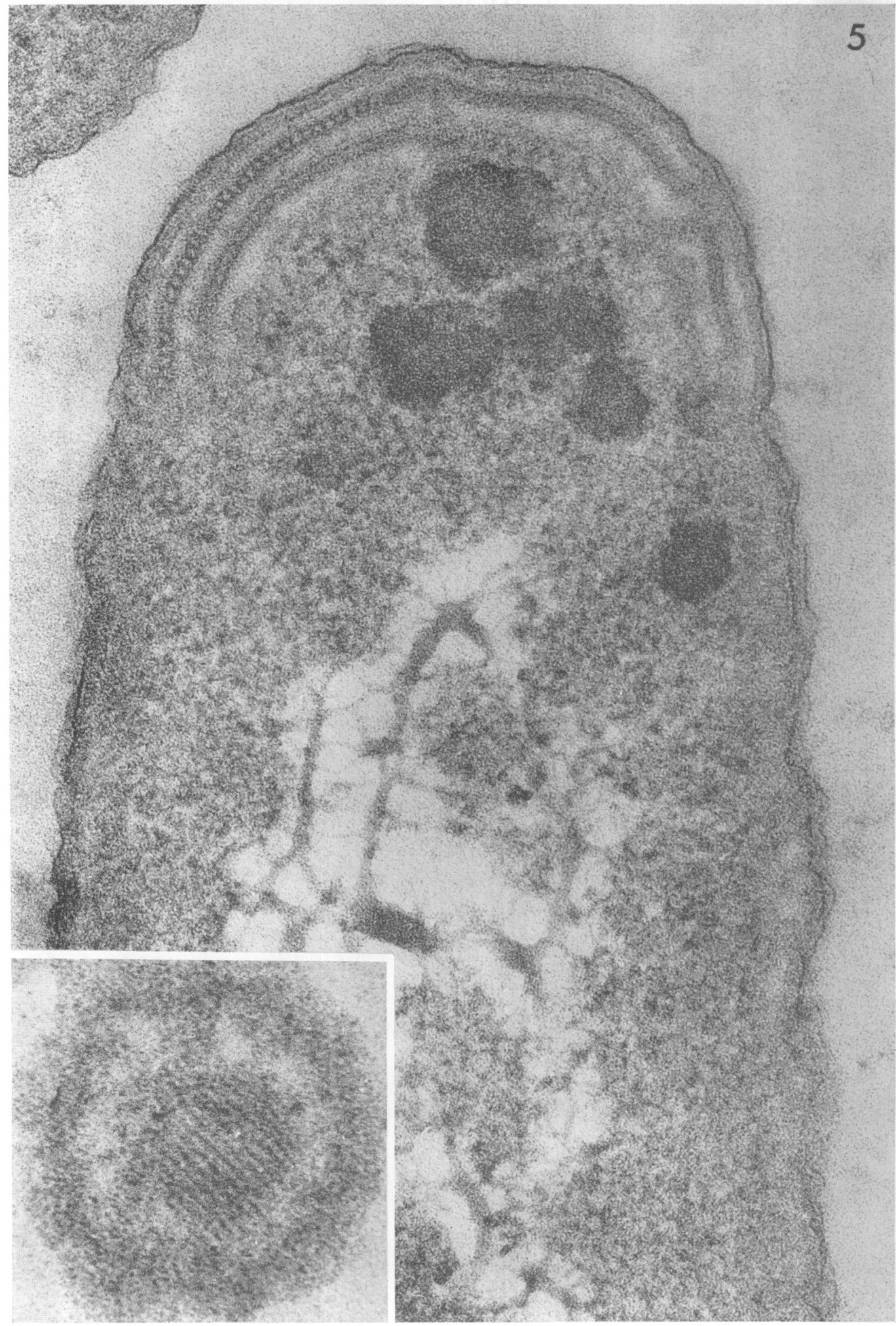

Fig. 5. Six hours after addition of magnesium. A septate membrane is evident near the top. The nature of the dense inclusions within the bacterial matrix is unknown. $\times 190,000$. The inset illustrates a section through the tip of a bacterium. $\times 200,000$. 
are perpendicular, thus revealing their lamellar nature and regular spacing at intervals of $100 \mathrm{~A}$.

Infoldings and reduplication of the plasma membrane have been described (Tomasz, Jamieson, and Ottolenghi, J. Cell Biol. 22:453, 1964; Conti and Hirsch, J. Bacteriol. 89:503, 1965; Murray and Watson, J. Bacteriol. 89:1594, 1965), but regularly spaced septa were not observed. However, two studies of Rhodospirillum rubrum fixed in osmium tetroxide (Cohen-Bazire and Kunisawa, J. Cell Biol. 16:401, 1963; Hickman and Frenkel, J. Cell Biol. 25:261, 1965) report "striae," which, although not clearly defined nor regular in spacing, may correspond to the septa described in the present paper. Although septate membranes are occasionally found in control bacteria, in magnesium-deficient bacteria, and in bacteria $3 \mathrm{hr}$ after addition of magnesium, they are not so extensive and generally contain less well-defined septa than those encountered in bacteria 6 or $9 \mathrm{hr}$ after addition of magnesium, when the process of ribosome synthesis is most active. Why the membranes undergo hypertrophy is unclear. Presumably, such membranes are not related to the production of RNA, for RNA synthesis precedes the assembly of ribosomes, which do not appear in appreciable numbers until after the $3 \mathrm{rd}$ hr. The observation that ribosomes are not aggregated on, or more numerous in, the vicinity of the membranes would tend to exclude the possibility that the membranes participate directly in the assembly of ribosomes.

\section{ACKNOWLEDGMENTS}

This investigation was supported by grants from the National Foundation, Inc., and was conducted under the auspices of the Commission on Influenza, Armed Forces Epidemiological Board. Support was also provided by the Office of Naval Research (Nonr 266(89)-NR103-574). 